\title{
Incidence, Bacteriological Profile and Antibiotic Resistance Pattern of Catheter Associated Urinary Tract Infections in a Tertiary Care Hospital
}

\author{
Kalaivani Ramakrishnan* (D), Jayapal Venugopal, Joshy M. Easow and M. Ravishankar
}

Department of Microbiology, Mahatma Gandhi Medical College and Research Institute, Sri Balaji Vidyapeeth, Deemed to be University, Puducherry, India.

\begin{abstract}
During the past three decades, especially in developed countries there are adequate and effective Hospital Acquired Infection (HAl) control programs and implementations are being focused. But in developing countries, due to lack of awareness and effective implementable infection control policies, there is no adequate comparative data to validate the safe healthcare delivery system. Thus this descriptive surveillance study was aimed to find the Incidence rate of Catheter Associated Infections (CA-UTIs) in a tertiary care hospital, Puducherry over a period of three years $(2016,2017$ \& 2018). From all confirmed CA-UTI cases, demographic details, patient distribution, bacteriological profile and antibiotic resistance pattern was aimed. Strict hand hygiene, aseptic practices and catheter bundle care approaches were meticulously emphasized and monitored regularly. The incidence rate of CA-UTI during 2016, 2017 and 2018 was calculated as 7.9, 4.8 and 2.9 per 1000 catheter days respectively. Male gender preponderance was noticed, with majority of age-group belongs to 61 years and above. E.coli and Klebsiella pneumoniae were found to be the commonest bacterial Uro-pathogens with moderate to high level resistance to various antibiotics tested. This study ensures that strict hand hygiene, appropriate and adequate usage of Personal Protective Equipment's (PPE), aseptic measures and adherence to infection control bundles will reduce the incidence and burden of CA-UTI.

Keywords: CAUTI, Bacterial isolates, Foley's catheter, Bundle care, Infection Control.
\end{abstract}

*Correspondence: kalaimicro21@gmail.com

(Received: 28 July 2019; accepted: 01 September 2019)

Citation: Kalaivani Ramakrishnan, Jayapal Venugopal, Joshy M. Easow and M. Ravishankar, Incidence, Bacteriological Profile and Antibiotic Resistance Pattern of Catheter Associated Urinary Tract Infections in a Tertiary Care Hospital, J Pure Appl Microbiol., 2019; 13(3): 1549-1554. https://doi.org/10.22207/JPAM.13.3.27

C The Author(s) 2019. Open Access. This article is distributed under the terms of the Creative Commons Attribution 4.0 International License which permits unrestricted use, sharing, distribution, and reproduction in any medium, provided you give appropriate credit to the original author(s) and the source, provide a link to the Creative Commons license, and indicate if changes were made. 


\section{INTRODUCTION}

Hospital Acquired Infections or Healthcare Associated Infections (HAl/HCAl), refers to infections associated with health care delivery in any settings (e.g. Hospitals, long-term care, and ambulatory settings) ${ }^{1}$. An infection is classified as HCAl, if it was not present or incubating at the time the patient was admitted to the health care facility or any new infection occurs more than 4872 hours after admission and within 10 days after discharge from a health care facility. And it must be related to the procedures, treatments or other events. Date of event may occur mostly before the patients discharge or after the discharge also ${ }^{2}$.

According to WHO, over 1.4 million people worldwide suffers at a time from infectious complications following $\mathrm{HCAl}^{3}$. Majority of the Health-care Associated Infections are due to lack/ inadequate infection control measures during insertion and maintenance of indwelling medical devices among the intensive care patients ${ }^{4-6}$. In the NHSN 2011 surveillance report, 45-79\% of patients in adult critical care units had an indwelling catheter ${ }^{3}$. According to CDC report, $12 \%-16 \%$ of adult inpatients will be with an indwelling urinary catheter, of which, $3 \%-7 \%$ will be with high risk of developing CA-UTI ${ }^{7}$. Among various Health-care Associate Infections, Catheter associated Urinary tract Infection (CA-UTI) is one of the major health issue worldwide. It significantly increases the morbidity and mortality of patients, especially in developing countries ${ }^{8}$.

CA-UTI leads to various complications like cystitis, pyelonephritis, uro-sepsis, prostatitis, epididymitis, orchitis, etc., ${ }^{7}$ It also causes significant emotional impact among the family members and patients. Markedly it increases the length of hospital stay, escalates the cost of healthcare expenditure and adds more pressure to the treating team. There are various predisposing/ risk factors for increase in incidence of HCAl rate in developing countries like, compromised sanitation, poor hand hygiene compliance, lack of trained personal for infection prevention, limited / lack of knowledge of proper use of PPE, compromised biomedical waste management policies and rampant misuse of antimicrobial agents ${ }^{9,10}$. This descriptive analysis of HCAl surveillance study was aimed to know the quality of health care delivery system persisting, So that preventive measures can be adopted to prevent such events in the near future. The aim of this study was to determine the incidence rate, patient's distribution, bacteriological profiling and antibiotic sensitivity pattern of CAUTI.

\section{MATERIALS AND METHODS}

In a tertiary care hospital, Puducherry, a descriptive targeted surveillance study was conducted, involving all adult in-patients with Foleys catheter for more than or equal to 48 hours. This study was done during January 2016 to December 2018. All in-patients who got urinary catheterization done outside the institute, patients less than 18 years, patients with urinary catheter other than Foley's catheter, patients with known UTI with or without treatment and adult with known sexually transmitted diseases were excluded.

\section{Method of data collection}

On a day-to-day basis, laboratory-based, as well as ward based, procedure directedtargeted HAI surveillance was done (using HCAI daily monitoring proforma) in all critical care areas and in all in-patient wards. Reports and data were periodically analyzed and on real-time, issues were critically analyzed. Following individual case based route cause analysis; corrective measures were taken and implemented immediately. And all the data were presented regularly at Hospital Infection Control Committee (HICC) meeting with corrective action report. Incidence rate of CAUTI was calculated using the quality indicator formula, i.e., Incidence Rate of CA -UTI = Number of Catheter Associated-UTI in each month /Number of Urinary Catheter Days in the same month $x$ 1000. During daily infection control ward rounds by infection control team members, for all patients with Foley's catheter, the following key parameters like, necessity to cauterization, strict adherence of hand hygiene, any indication to remove the catheter at the earliest, maintenance of closed drainage system, position of urobags below the waist, adequate daily catheter maintenance care and whether aseptic measures followed meticulously were monitored and documented without compromise. Infection control training was given and insisted among all Health-care workers (HCWs) regularly throughout this study period and maintained. The CAUTI incidence rate, patient distribution, bacteriological profiling and 
antibiotic resistance pattern were analyzed using the software Epi-Info version 7.2. Institute Human Ethical Committee clearance was obtained without any conflict of interest.

\section{RESULTS AND DISCUSSION}

During 2016, the overall incidence rate of CA-UTI was estimated to the highest of 7.9 CA - UTIs per 1000 Catheter Days. But in 2017 the incidence rate was 4.8 CA - UTIs for 1000 Catheter Days. Virtually, a study from Puducherry documented CAUTI rate of 6.1 per 1000 device days ${ }^{11}$. According to International Nosocomial Infection Control Consortium, CDC (INICC) report, during 2007 and 2012 involving 43 countries in a device associated module, the overall CAUTI rate per 1000 catheter days was 5.3 in adult and paediatric ICU ${ }^{12}$. Over the course of study period, in 2018 the incidence rate of CA-UTI was determined as 2.9 CA-UTI per 1000 Catheter days (Table 1). According to INICC India, data for HAI rates which was published in 2016 representing pooled data of 40 hospitals from 20 cities in India (10 years data) states that, the pooled CA-UTI rate was 2.13 per 1000 device days ${ }^{13}$. Month-wise distribution of CA-UTI incidence showed uniform peak during July and September, which could be due to the new batch of staffs and residents recruitment. However, the incidence of CA-UTI during the period of 2016 to 2018 was compared and it was found to be statistically very significant with P value of 0.001 (Table 1 ).

The CA-UTI rate by CDC NHSN data for 2013 got reported as 2.1 per 1000 catheter days ${ }^{14}$. As the CDC's NSHN HAl surveillance guidelines was globally accepted to follow, their data can be considered as a benchmark to compare our $\mathrm{HAI}$ rates along with national and state HAI data available. Very fortunately, our CA-UTI incidence rate in 2018 was almost equally similar to the CDC and INICC data ${ }^{13,14}$. This was achievable only by constant individual case-based route-cause analysis and continuous education to the various levels of Health-care workers in our institute over the course of this study, especially to all the staff nurses and residents posted in all intensive and emergency care areas. With continues reenforcement and close direct monitoring of Foley's catheter insertion and daily catheter care by following strict adherence to Catheter insertion and maintenance bundle care approach, this bench mark scale was made to achieve among our patients ${ }^{15-17}$.

Table 1. Incidence rate of CA- UTI year-wise distribution

\begin{tabular}{lccc}
\hline & Incidence Rate of CA - UTI Year-wise distribution & \multicolumn{2}{c}{ (CA - UTIs per 1000 Catheter Days) } \\
Months & 2016 & 2017 & 2018 \\
\hline January & 5.3 & 6.3 & 1.8 \\
February & 7.8 & 3 & 4.3 \\
March & 6.4 & 19.6 & 2.7 \\
April & 3 & 8.5 & 5.1 \\
May & 14.2 & 4.8 & 3.3 \\
June & 8.2 & 1.6 & 0 \\
July & 15 & 5.8 & 9 \\
August & 5.6 & 1.5 & 0 \\
September & 10.6 & 4.6 & 3.3 \\
October & 8 & 1.7 & 0 \\
November & 10.3 & 1.9 & 2.7 \\
December & 2.8 & 7 & 2.9 \\
Incidence rate of CA-UTI & 7.9 & 4.8 & $(22 \times 7514) \times 1000)$ \\
Comparison of incidence & $(42 / 5295) \times 1000)$ & $(29 / 6003) \times 1000)$ & \\
between 2016 \& 2017 & & $X^{2}=2.08, \mathrm{p}=0.037$ & \\
Comparison of incidence & & $X^{2}=1.79, \mathrm{p}=0.073$ & \\
between 2017 \& 2018 & & $X^{2}=3.9, \mathrm{p}=0.001$ & \\
Comparison of incidence & & & \\
from 2016 to 2018 & & &
\end{tabular}


Out of these patients with CA-UTI, majority of $(69 \%)$ them were found to be male gender and followed by $31 \%$ of female patients. Among our 93 CA-UTI patients, majority (27\%) of the patients belongs to 61 years and above followed by $50-60$ years $(25 \%)$ of age group. During 2016, the peak incidence was observed with age group $42-49$ years $(29 \%)$ and in 2017 \& 2018 highest of $31 \%$ and $32 \%$ peak was documented among age group of $61 \&$ above (Fig. 1). Department-wise analysis of CA-UTI cases showed that the incidence was high in the department of General Medicine in all the three years 2016, 2017 \& 2018 with 33\%, 38\% and 45\% respectively. Followed by Orthopedics, $28 \%, 24 \%$ and $23 \%$ CA-UTI cases got documented during the study period respectively. Expect in 2016 (17\%), during 2017 and 2018 from department of General Surgery lowest incidence was observed $(7 \%$ and 9\%) (Table 2). This departmental variations in incidence could be because of their underlying comorbid/ primary predisposing clinical conditions like, uncontrolled diabetes mellitus, uncontrolled hypertension, chronic neurological disorders, cerebrovascular accidents, etc., The most common clinical diagnosis among patients with CA-UTI in orthopedics department was found to be road traffic accidents with poly trauma, total hip- replacement, quadriplegia, cord-syndrome, cervical myopathy etc.,

Among General Surgery patients, the commonest diagnosis was perforation peritonitis, acute/chronic pancreatitis, necrotizing fasciitis and cellulitis. In-case of Neurosurgery patients, head injury and SDH was found to be the commonest cause for chronic urinary catheterization. Among all these 93 CA-UTI patients, the average Foley's

Table 2. Department-wise distribution of patients with CA-UTI

\begin{tabular}{lccc} 
Department-wise distribution of CAUTI patients \\
Departments & 2016 & 2017 & 2018 \\
\hline $\begin{array}{l}\text { General Medicine } \\
\text { General Surgery }\end{array}$ & $33 \%$ & $38 \%$ & $45 \%$ \\
$\begin{array}{l}\text { Obstetrics \& Gynecology } \\
\text { (OBG) }\end{array}$ & $17 \%$ & $7 \%$ & $9 \%$ \\
Orthopedics & $10 \%$ & $9 \%$ \\
Neurosurgery & $28 \%$ & $24 \%$ & $23 \%$ \\
& $10 \%$ & $21 \%$ & $14 \%$
\end{tabular}

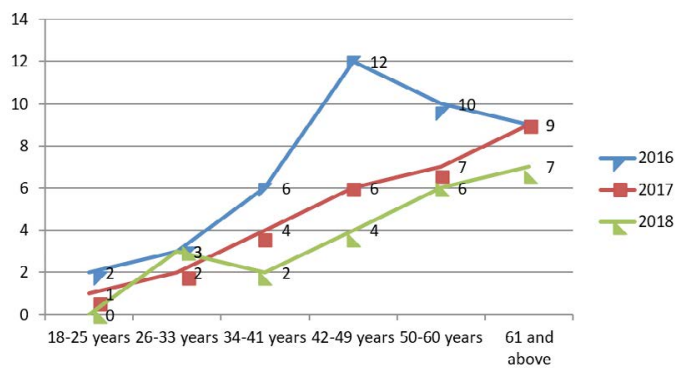

Fig. 1. Age-wise distribution of CA-UTI patients from 2016- 2018

catheterization days to develop catheter associated UTI was found to be 3 to 12 days.

All these documented, 93 CAUTI patients urine samples showed significant growth of $\geq 10^{5} \mathrm{CFU} / \mathrm{ml}$. Similar to others, E.coli was the most common isolate, followed by Klebsiella pneumoniae and followed by other organisms (Fig. 2) ${ }^{18}$.

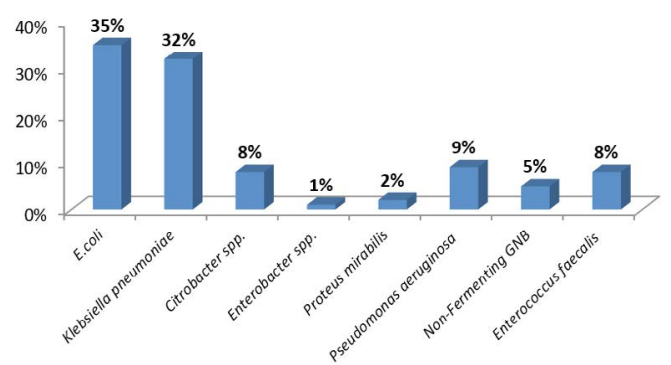

Fig. 2. Distribution of aerobic bacterial isolates from patients with CA-UTI

Among Enterobacteriaceae, E.coli was found to be a maximum of $82 \%$, followed by $57 \%$ of Klebsiella Pneumoniae isolates were found to be resistant to Ceftriaxone / Cefotaxime. In contrast, the resistance pattern of INICC report (2007-2012) says that only $63 \%$ of E.coli and $68.4 \%$ of Klebsiella pneumoniae isolates only showed resistance towards $3^{\text {rd }}$ generation cephalosporins ${ }^{12}$. But in case of aminoglycoside (47\% gentamicin, $43 \%$ amikacin) and carbapenem (60\% imipenem, 37\% meropenem) resistance, Klebsiella pneumoniae was found to be more resistant than E.coli (Table 3). Again unfortunately, when compared to INICC consortium report, our Klebsiella pneumoniae and E.coli isolates showed very significant resistance rate towards carbapenems, which is of great alarm in the near future. Towards fluoroquinolone resistance, $85 \%$ of E.coli isolates were found to 


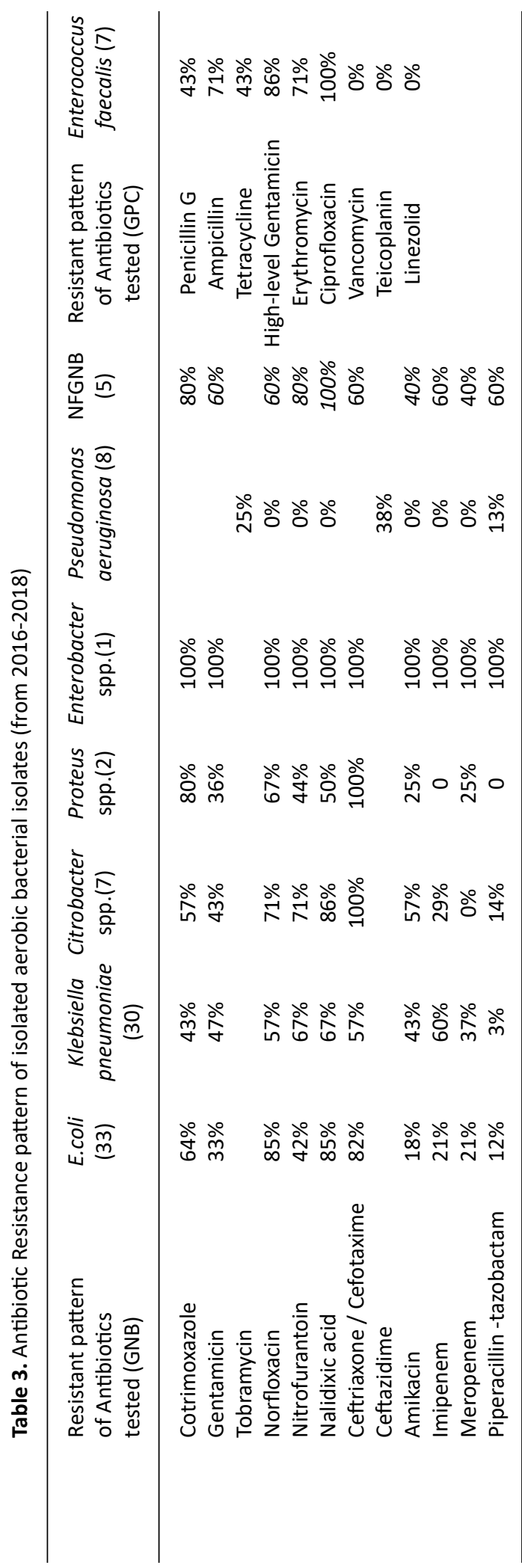

be resistant; this data was less similar to INICC consortium antimicrobial resistance report ${ }^{12}$.

The HAl surveillance activities need to be a combination of both Outcome and Process based surveillance to achieve the target effectively. As there is an urgent increasing need to pool the national HAI data, to do root cause analysis, to formulate implementable infection prevention strategies and to prevent $\mathrm{HAl}$ in the future, a proactive surveillance networking among all healthcare system needs to be insisted. Strict hand hygiene practices, bundle care approach and continuous re-enforcement of infection control measures among all the HCW's will be the effective HAI preventive measures.

\section{CONCLUSION}

During the three years study period, with strict hand hygiene practices, use of closed drainage system, by implementing and monitoring the catheter insertion and maintenance bundle, strict aseptic non-touch practice and policy adherence monitoring practices, the incidence rate from 7.9 per 1000 catheter days significantly reduced down (2.9 per 1000 catheter days) very close to the benchmark. E.coli and Klebsiella pneumoniae were found to be the most common bacterial pathogen to cause CA-UTI. The moderate to high level of antimicrobial resistance pattern among the uropathogenic isolates creates a great alarming sign for all the stakeholders. Sound knowledge about the need and impact of HAls and strict aseptic measures may act as a tool to prevent the incidence of device associated infections.

\section{ACKNOWLEDGMENTS}

We sincerely acknowledge our SBV, Deemed to be University for supporting this faculty project. We would also like to thank Dr. G. Ezhumalai, Sr. Statistician \& Research Consultant, SBVU for his support and contributions. Finally we thank all our Infection Control Nurses for their effective involvement. We wholeheartedly thank our Medical Superintendent for permitting us to carry out this study successfully.

\section{CONFLICT OF INTEREST}

The authors declare that there is no conflict of interest. 


\section{AUTHORS' CONTRIBUTION}

KR and JV did the primary investigation. KR did the study, compiled the data and analyzed the result and drafted the manuscript. JME did the literature review and contributed intellectually throughout the course of this study. MR took care of quality of this research. All the authors contributed and approved the manuscript for publication.

\section{FUNDING}

None.

\section{DATA AVAILABILITY}

All datasets generated or analyzed during this study are included in the manuscript.

\section{ETHICS STATEMENT}

For conducting this study and publishing the analyzed data, Institute Research committee and Institute Human Ethical Committee clearance was obtained.

\section{REFERENCES}

1. Siegel, J.D., Rhinehart, E., Jackson, M., Chiarello, L. The Healthcare infection control practices advisory committee guideline for isolation precautions: Preventing transmission of infectious agents in healthcare settings. Atlanta, GA: centres for disease control and prevention, 2007. https://doi. org/10.1016/j.ajic.2007.10.007

2. NizamDamani. Manual of Infection prevention and control, Third edition, chapter 3, Surveillance. Oxford University Press:2012;25-31.

3. WHO. World Alliance for Patient Safety. The Global Patient safety challenge 2005-2006 'Clean Care is Safer Care'. Geneva, Switzerland: WHO, 2005.

4. Hooton M.T., Suzanne F., Bradley S.F, Diana D. Cardenas.DD, Colgan R, Suzanne E. et.al., Diagnosis, Prevention, and Treatment of Catheter International Clinical Practice Guidelines from the Infectious Diseases Society of American Associated Urinary Tract Infection in Adults: -IDSA Guidelines :2009.

5. Ronald AR, Nicolle LE, Stamm E, Krieger J, Warren J, et al. Urinary tract infection in adults: research priorities and strategies. Int J Antimicrob Agents 2001; 17: 343348. https://doi.org/10.1016/S0924-8579(01)00303-X

6. Вагіsіт Z, Babiт-Erceg A, Borziт E, Zoraniт V, Kaliterna V, et al. Urinary tract infections in South Croatia: aetiology and antimicrobial resistance. Int J Antimicrob Agents 2003; 22 Suppl 2: 61-64. https://doi.org/10.1016/
S0924-8579(03)00233-4

7. Catheter-associated Urinary Tract Infections (CAUTI) / $\mathrm{HAl} / \mathrm{CDC}$. January 2019. Available from :http://www. cdc.gov/hai/ca uti/uti.html.

8. Prakash SS, Rajshekar D, Cherian A Sastry AS. Care bundle approach to reduce device-associated infections in a tertiary care teaching hospital, South India. J Lab Physicians. 2017; 9(4):273-278. https:// doi.org/10.4103/JLP.JLP 16216

9. Graves N, Tong E, Morton AP, Halton K, Curtis M, et al. Factors associated with health care-acquired urinary tract infection. Am J Infect Control, 2007; 35: 387-392. https://doi.org/10.1016/j.ajic.2006.09.006

10. Kollef,M.H.SMART approaches for reducing nosocomial infections in the ICU. Chest 2008; 134: 447-456. https://doi.org/10.1378/chest.08-0809

11. Deepashree R, Raghavan R, Sastry AS. Implementation of active surveillance system to track hospital-acquired infections in a tertiary care hospital in India. J Curr Res Sci Med 2017; 3:21-8. https://doi.org/10.4103/jcrsm. jcrsm_16_17

12. Rosenthal VD, Maki DG, Mehta $Y$, Leblebicioglu $\mathrm{H}$, Memish ZA, AlMousa $\mathrm{HH}$., et al. International Nosocomial Infection Control Consortium (INICC) report, data summary of 43 countries for 2007-2012. Device-associated module. Am J Infect control: 2014(42), 942-56.

13. Mehta Y, Jaggi N, Rosenthal VD, Kavathekar M, Sakle A, Munshi N, et al. Device-associated infection rates in 20 cities of India, data summary for 2004-2013: Findings of the International Nosocomial Infection Control Consortium. Infect Control HospEpidemiol 2016; 37: 172-81. https://doi.org/10.1017/ice.2015.276

14. Dudeck MA, Weiner M, Aen-Bridson K, Malpiedi PJ, Peterson KD, Pollock DA, et al. National Healthcare safety Network (NHSN) report, data summary for 2012, Device-associated module. AmJ Infect Control 2013; 41:1148-66. https://doi.org/10.1016/j. ajic.2013.09.002

15. Blanck $A M$, Donahue $M$, Brentlinger $L$, Dixon Stinger $\mathrm{K}$, Polito C. A quasi experimental study to test a prevention bundle for catheter associated urinary tract infections. J HospAdm 2014; 3:101-8. https:// doi.org/10.5430/jha.v3n4p101

16. Davis KF, Colebaugh AM, Eithun BL, Klieger SB, Meredith DJ, Plachter $\mathrm{N}$, et al. Reducing catheter associated urinary tract infections: A quality improvement initiative. Pediatrics 2014; 134:e857 64. https://doi. org/10.1542/peds.2013-3470

17. Clarke K, Tong D, Pan Y, Easley KA, Norrick B, Ko C, et al. Reduction in catheter associated urinary tract infections bybundling interventions. Int J Qual Health Care 2013; 25:43 9. https://doi.org/10.1093/intqhc/ mzs077

18. Manikandan S, Ganesapandian S, Singh M, Kumaraguru AK Antimicrobial susceptibility pattern of urinary tract infection causing human pathogenic bacteria. Asian $\mathrm{J}$ Med Sci 2011; 3: 56-60. 